\title{
Sevoflurane or halothane could be used for intellectually disabled children under day-stay general anaesthesia
}

\author{
Is there any difference in postoperative morbidities for $24 \mathrm{~h}$ following dental \\ care under day-stay general anaesthesia using sevoflurane or halothane in \\ intellectually disabled children?
}

Ersin NK, Önçag O, Cogulu D, Çiçek S, Balcioglu ST, Çökmez B. Postoperative morbidities following dental care under day-stay general anaesthesia in intellectually disabled children. J Oral Maxillofac Surg 2005; 63:1731-1736

Design This reports on a randomised controlled trial conducted in Turkey.

Intervention Children were recruited to the trial who had intellectual disabilities and who underwent general anaesthesia for their dental treatment. Anaesthesia was randomly assigned to be maintained with sevoflurane $(2.0-3.0 \%)$ or halothane (1.0-1.5\%) after participants received inhalation induction either with sevoflurane (8.0\%) or halothane $(5.0 \%)$ and nitrous oxide in oxygen (50:50). Immediately after induction, a suppository of diclofenac was given to all patients. The children also received fentanyl, atropine and atracurium besylate intravenously.

Outcome measures The time required for recovery (measured using the Aldrete Scale) and the length of time taken before they were discharged (the postanaesthetic discharge scoring system) from the hospital were noted. Pain and agitation were recorded using a visual analogue scale (0 to 10). Other postoperative morbidities, including crying, nausea and vomiting, bleeding and drowsiness, were also noted for $24 \mathrm{~h}$ after the operation.

Results A total of 86 intellectually disabled children were recruited. Forty-two children received sevoflurane whereas 44 received halothane. The most common morbidities during the postoperative $24 \mathrm{~h}$ were agitation and pain, and their occurrence was significantly more common in the sevoflurane group than in the halothane group $(P<0.05)$. The recovery time was shorter in the sevoflurane group, but the difference was not statistically significant. There was no difference between the groups in the discharge time.

Conclusions Apart from more postoperative agitation and pain after awakening from sevoflurane, the quality of recovery was similar between sevoflurane and halothane in the recovery room and at home during the first $24 \mathrm{~h}$.

\section{Commentary}

Day-stay general anaesthesia is a well-accepted treatment modality for the provision of comprehensive dental care in children with learning disabilities. This paper compares the postoperative morbidities of the volatile agents sevoflurane and halothane in such a situation. The documented high incidence of cardiac arrhythmias in paediatric halothane anaesthesia, ${ }^{1,2}$ together with the UK Committee on Safety of Medicines recommendations regarding hepatotoxicity, has led to a significant reduction in its use in the UK but it is still commonly used in a number of other countries.

A partially blinded technique was used in this study of 86 children who had a mean age of 11 years and the majority of whom $(82 \%)$ had moderate to profound learning disabilities. Details of the computer-generated randomisation method used were not reported. The main clinical outcome measures were recovery time, time to discharge and postoperative (within $24 \mathrm{~h}$ ) morbidities. The same team of three dentists carried out all the dental treatment, but it is unclear if the anaesthetic team similarly remained unchanged throughout the study. The recovery nurse and the dentist who telephone-interviewed the children's parents on the first postoperative day where blinded to the study group.

Although the importance of pre-emptive antiemetics, fluid balance and analgesia is recognised, the authors do not appear to have used these optimally in the trial, which compromises the findings. The patients are also categorised by degree of impairment but this is not applied to stratify the findings. It is possible that some outcome measures, such as agitation, and the assessment of pain would be influenced by the nature and degree of the patient's disability.

The statistically significant increase in immediate postoperative pain and agitation in the sevoflurane group may be explained by the more rapid emergence compared with halothane. ${ }^{3}$ There is no explanation given for this difference continuing throughout the following $24 \mathrm{~h}$. Although this could result from a lack of balance between the groups in terms of the dental treatment and local analgesia provided, as the authors state, the mean amount of treatment and local analgesia was the same between the groups.

This is an interesting study which addresses the important issue of the delivery of dental care to children with learning disabilities. It confirms that sevoflurane is a safe alternative to halothane and is appropriate in the provision of general anaesthesia for children with learning disabilities.

\section{Practice point}

- Sevoflurane is a safe alternative to halothane and is appropriate in the provision of general anaesthesia for children who have learning disabilities.

\section{Avril Macpherson}

Special Care and Sedation Department, Lothian Salaried Primary Care Dental Service, Edinburgh, Scotland, UK

1. Paris ST, Cafferkey M, Tarling M, Hancock P, Yate PM, Flynn PJ. Comparison of sevoflurane and halothane for outpatient dental anaesthesia in children. $\mathrm{Br}$ J Anaesth 1997; 79:280-284.

2. Blayney MR, Malins AF, Cooper GM. Cardiac arrhythmias in children during outpatient general anaesthesia for dentistry: a prospective randomised trial. Lancet 1999; 354:1836-1837.

3. Keaney A, Diviney D, Harte S, Lyons B. Postoperative behavioural changes following anaesthesia with sevoflurane. Paediatr Anaesth 2004; 14: 866-870.

Evidence-Based Dentistry (2006) 7, 37

doi:10.1038/sj.ebd.6400408 